\section{НЕКОТОРЫЕ СЛОЖНЫЕ ВОПРОСЫ МЕТОДИКИ ОБУЧЕНИЯ ТУВИНСКОМУ ЯЗЫКУ КАК НЕРОДНОМУ}

\author{
Надежда Д. Сувандии, \\ Елена М. Куулар \\ Тувинский государственный \\ университет, \\ Российская Федерация
}

\section{SOME COMPLICATIONS IN THE METHODOLOGY OF TEACHING TUVAN TO NON-NATIVE SPEAKERS}

\author{
Nadezhda D. Suvandii, \\ Elena M. Kuular \\ Tuvan State University, \\ Russian Federation
}

В основе языковой политики Республики Тыва сформулирована стратегия сохранения и распространения тувинского языка - как государственного на территории республики и принята Государственная Программа развития и сохранения тувинского языка с 2017 по 2020 г2. Одной из актуальных проблем методики преподавания тувинского языка в ней признано преподавание тувинского языка как неродного. Но при этом отсутствуют специальные научные исследования по обучению тувинскому языку как неродному в общей методике преподавания тувинского языка.
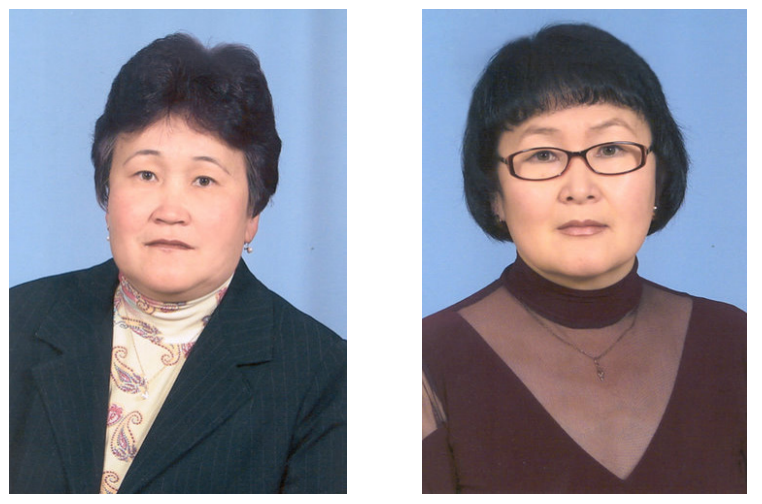

The foundation of the language policies of the Republic of Tuva is based on strategy of preserving and distributing the Tuvan language as a state language in the territory of Tuva, declared in the State Program for Developing and Preserving the Tuvan Language for the period from 2017 to 2020. One of the named pending problems of methodology of teaching Tuvan is teaching Tuvan to non-

Сувандии Надежда Дарыевна - кандидат филологических наук, доцент кафедры тувинской филологии и общего языкознания Тувинского государственного университета. Адрес: 667004, Россия, г. Кызыл, ул. Студенческий квартал 5, каб. 118. Тел.: +7 (394-22) 5-22-50; +7 (923) 268-93-69. Эл. адрес: suvandiin@mail.ru

Куулар Елена Мандан-ооловна - кандидат филологических наук, доцент кафедры тувинской филологии и общего языкознания Тувинского государственного университета. Адрес: 667004, Россия, г. Кызыл, ул. Студенческий квартал 5, каб. 213. Тел.: +7 (923) 263-46-85. Эл. адрес: kuular-e-m@mail.ru

Suvandii Nadezhda Daryevna, Candidate of Philology, Associate Professor, Department of Tuvan Philology and General Linguistics, Tuvan State University. Postal address: Office 118, 5 Studencheskii Kvartal St., 667004, Kyzyl, Republic of Tuva, Russian Federation. Tel.: +7 (394-22) 5-22-50; +7 (923) 268-93-69. E-mail: suvandiin@mail.ru

Kuular Elena Mandan-oolovna, Candidate of Philology, Associate Professor, Department of Tuvan Philology and General Linguistics of the Tuvan State University. Postal address: Office 213, 5 Studencheskii Kvartal St., 667004, Kyzyl, Republic of Tuva, Russian Federation. Tel.: +7 (923) 263-46-85. E-mail: kuular-e-m@mail.ru 
Перед педагогами, которые занимаются обучением тувинского языка как неродного, стоит нелегкая задача решения данной проблемы.

В статье описываются некоторые вопросы методики обучения русскоязычного населения Тувы и иностранных граждан тувинскому языку. Материалом выступил педагогический опыт авторов 2016-2017 г2.

Наличие среди 36 букв тувинского алфавита трех специфических букв ө, ү, н ставит особой задачей овладение их произношением. Одним из трудных вопросов при обучении тувинскому языку для русских учащихся является наличие долгих и фарингализованных гласных. В письме долгие гласные обозначаются двумя одинаковыми буквами, неподготовленные слушатели произносят эти гласные как два отдельных звука. Особое внимание при обучении тувинскому языку следует обратить на специфические звуки, при артикуляции которых активно участвует глотка. В тувинском языке эти звуки называются фарингализованными. При этом, фарингализация гласных считается существенной особенностью вокализма тувинского языка, по сравнению с другими тюркскими языками. Немалую трудность в обучении тувинском языку также составляет вопрос усвоения гармонии гласных, которая является характерной особенностью тюркских языков. Существенной особенностью тувинского языка в области согласных считается наличие сильных придыхательных согласных.

Авторы полагают, что исследовательская работа в области методических основ должна быть продолжена, а педагогам также важно специильное обучение, повышение квалификации.

Ключевые слова: Тува; тувинский язык, методика преподавания; родной язык; второй язык; русский язык; русскоязычное население; русские; русские Тувы; тюркские языки; тувинский алфавит; фонетика; фарингализация; долгие гласные native speakers. At the same time, we leak special scientific studies in teaching the Tuvan language to non-native speakers in common methodologies of teaching Tuvan. Teachers giving Tuvan language to non-native speakers are facing a challenge of solving this issue.

Article describes some aspects in methodology of teaching Tuvan to Russian-speaking residents of Tuva and foreigners. It is based on the authors' expertise in 2016-2017.

Special letters $\theta, y, \mu$ among 36 letters of Tuvan alphabet present a special task of learning their pronunciation. One of most challenging tasks for Russian-speakers in learning Tuvan is assimilation of long and pharyngealized vowels. Long vowels in writing are presented with paired same letters and extemporaneous students would try to pronounce them as two sounds. Special attention when learning Tuvan should be paid to specific sounds articulated with throat. In Tuvan language these vowels are called pharyngealized. In comparison with other Turkic languages pharyngealization is a distinctive feature of language vocalism in Tuvan. Another challenge in learning Tuvan is assimilation of harmony of vowels - a distinctive feature of all Turkic languages. Another significant feature of Tuvan language is presence of strong aspirate consonants.

Authors believe that studies in methodological basis should be continued and it is essential for teachers to receive a special education and additional training.

Keywords: Tuva; Tuvan language, methods of teaching; mother tongue; second language; Russian language; Russian-speaking population; Russians; Russians in Tuva; Turkic languages; Tuvan alphabet; phonetics; pharyngealization; long vowels

\section{Введение}

По инициативе Народного писателя Тувы Александра Александровича Даржая в Республике Тыва с 2016 года ежегодно 1 ноября отмечается День тувинского языка, учрежденный Указом Председателя Правительства Республики Тыва Ш. В. Кара-оолом. Основной целью Дня тувинского языка являются сохранение, поддержка и развитие тувинского языка как государственного языка Республики Тыва и неотъемлемой части культурного и духовного наследия тувинского народа. 
В рамках проведения Дня тувинского языка ректор Тувинского государственного университета, профессор О.М. Хомушку предложила проводить в главном вузе республики курсы тувинского языка для русскоязычной аудитории.

В 2016 г., в день проведения I форума, посвященного Дню тувинского языка, было проведено первое занятие тувинского языка с участием членов правительства Тувы, депутатского корпуса и профессорско-преподавательского состава университета. Проведение первого занятия было доверено доценту кафедры тувинской филологии и общего языкознания Н. Д. Сувандии, одному из соавторов данной статьи.

На первом занятии, которое состоялось 1 ноября 2016 г., присутствовали заместители Председателя Правительства Тувы А. А. Брокерт, М. В. Тунев, депутат городского Хурала представителей Р. С. Поманисочкин, проректоры Тувинского госуниверситета Л. К. Будук-оол, А. А. Стороженко и др. (Вицепремьеры ..., 2016: Электр. ресурс).

В статье описываются некоторые вопросы методики обучения тувинскому языку как неродному из данного опыта работы авторов, а также из других занятий с русскоязычным населением Республики Тыва и иностранными гражданами.

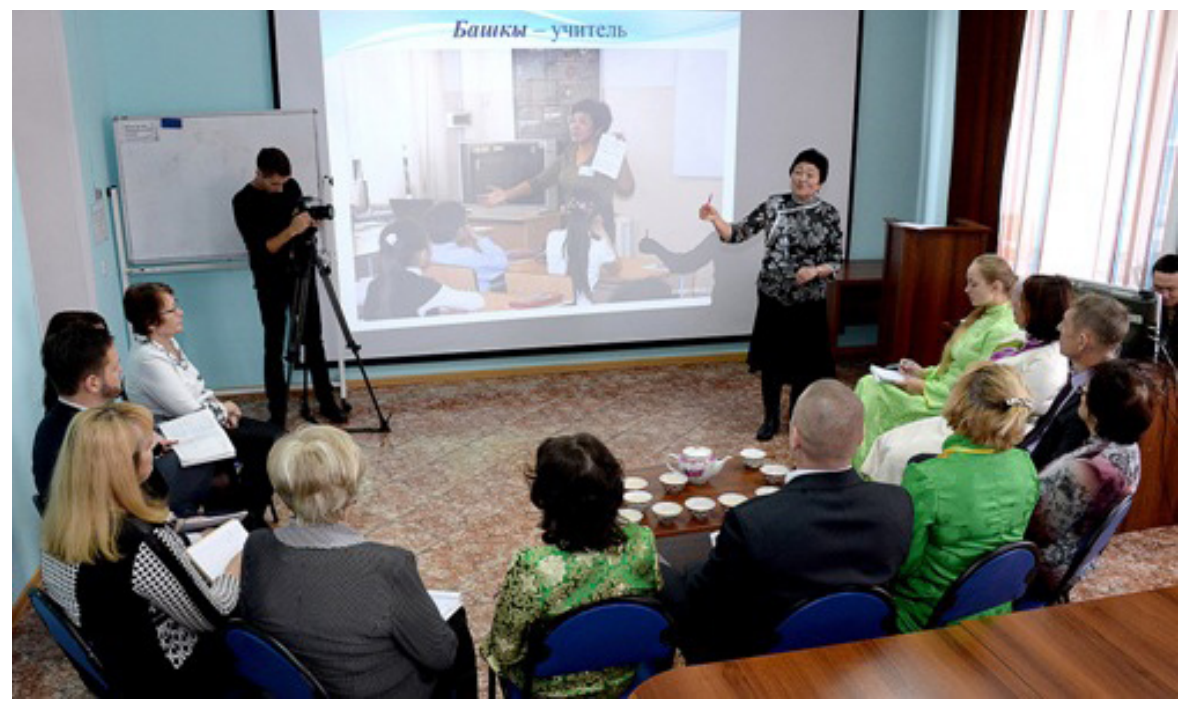

Фото 1. На занятии 1 ноября 2016 г. в Тувинском государственном университете. Фото пресс-службы Правительства Республики Тыва. Photo 1. A lesson on Nov. 1, 2016 at Tuvan State University.

Photo by the Press-Service of the Government of the Republic of Tuva

\section{Особенности обучения тувинскому языку}

В основе языковой политики Республики Тыва сформулирована стратегия сохранения и распространения тувинского языка - как государственного на территории республики и принята Государственная Программа развития и 
сохранения тувинского языка с 2017 по 2020 гг. Одной из актуальных проблем методики преподавания тувинского языка в ней признано преподавание тувинского языка как неродного. Но при этом отсутствуют специальные научные исследования по обучению тувинскому языку как неродному в общей методике преподавания тувинского языка. Перед учеными, которые занимаются обучением тувинского языка как неродного, стоит нелегкая задача решения данной проблемы.

Первые научные работы по методике преподавания тувинского языка были разработаны в 1960-х гг. К ним относятся следующие работы: К. Х. Оргу «Тыва дылды ортумак школага башкылаарының методиказы» («Методика преподавания тувинского языка для средней школы (для учителей)») (Оргу, 1967), К. Б. Март-оол «Методика преподавания местоимения родного языка в 5 классе тувинских школ» (Март-оол, 1969), «5-9 класстарга тыва дылды башкылаарының методиказы» («Методическое пособие для учителей тувинского языка для 5-9 классов») (Март-оол, 2002), Е. Л. Иргит «Обучение орфографии тувинского языка в 5-6 классах в диалектных условиях» (Иргит, 1996; Март-оол, 2002).

Но эти работы подразумевают обучение тувинскому языку как родному. Обучение тувинскому языку как неродному имеет свою специфику. Основной целью проведения занятий является формирование первичных умений и навыков тувинской устной речи, использование диалога культур разных национальностей, как основного орудия познания мира через родной язык.

Методика иноязычного образования имеет свои особенности, как теоретические, так и практические.

В качестве теоретических оснований, в частности, следует отметить то обстоятельство, что тувинский язык в зависимости от отношения обучающегося к нему, может рассматриваться как иностранный, или как не родной, но второй язык. При этом родным языком мы рассматриваем тот язык, на котором с человеком с рождения разговаривают в семье и которым человек овладевает свободно и думает на нем. В многонациональной России, особенно в регионах, где разговаривают на нескольких языках различные этнокультурные общности, дети могут овладевать языками с ранних лет и разделить для них родной или не родной язык становится сложнее. Но при этом отличить их от иностранного языка проще, поскольку иностранный язык изучается вне условий его естественного бытования, вне культуры. А второй язык входит в поле коммуникаций человека, в его бытовое окружение. Так, например, для русскоязычных жителей Тувы тувинский язык является не иностранным, а вторым языком, который они слышат практически повсеместно.

Принцип дифференциированного подхода к обучающимся в обучении языком, который относится к общеметодическим принципам (Теоретические 
основы ..., 2017: Электр. ресурс) также может выражаться в учете групп учащихся в зависимости от их родного языка. Так, в частности, как мы уже сказали, для русскоязычных жителей Тувы тувинский язык может выступать вторым языком социокультурного окружения, но при этом является языком достаточно сложным для обучения, поскольку относится к иной языковой семье. По классификации Н.А.Баскакова, тувинский язык относится к уйгуро-тукюйской подгруппе восточнохуннской ветви тюркских языков (Баскаков, 1952). Тувинский язык - один из младописьменных современных тюркских языков. Он будет иностранным для жителей других стран, но для тюркоязычных народов он будет близким, более легким для обучения (также, как и для тувинцев - почти любые тюркские языки). То есть речь идет о сходстве и различиях систем контактирующих языков, которые изучает и учитывает сопоставительная лингвистика. Знания об этой специфике, как пишет Т. И. Скрипникова, необходимо учитывать при организации обучения тому или иному языковому материалу, в частности в системах грамматики, фонетики и т. д. (Теоретические основы ..., 2017: Электр. ресурс).

В данном случае мы изложим особенности тувинского языка, которые становятся значимыми для русскоязычных обучающихся, полагая, что исследовательская работа в области методики может быть обозначена здесь, а впоследствии развита и углублена в разных направлениях.

\section{Особенности тувинского языка для русскоязычных учащихся}

В первую очередь отметим тот факт, что тувинский алфавитбыл создан в 1930 г. Н. Н. Поппе на основе латинской графики, а в 1941-1943 гг. был осуществлен переход на кириллицу. Такое «приближение» тувинского языка к русскому языку имело политические причины, в виду постепенного политического, социально-экономического сближения Тувы с Россией (завершившегося вхождением республики в состав СССР в 1944 г.). Как и с другими языками союзных территорий, подобные реформы имели и практический смысл: так было проще издавать книги, вести документооборот и преподавать в школах параллельно два языка - русский и национальный.

Кириллическая основа тувинского алфавита позволяет нашим обучающимся легче осваивать чтение. Однако, один нюанс - наличие среди 36 букв трех специфических букв $\theta, \chi, \mu$ - ставит особой задачей овладение их произношением.

На первом занятии мы особое внимание уделяли этому с использованием аудиовизуальных средств. С помощью слайдов мы показывали артикуляцию, характеристику данных звуков и картинки, в названии которых присутствуют данные звуки. 
Как это излагается в нашей методике?

[Ө] - переднеязычный широкий гласный звук. При произношении этого звука губы необходимо округлить и вытянуть вперед: өг - 'юрта', өл - 'мокрый', хөл - 'озеро'.

[Y] - переднеязычный узкий гласный звук. При произношении данного звука губы округлены и вытянуты вперед: үгү - 'сова', $ү щ$ - 'три', сүт - 'молоко'.

$[\mathrm{H}]$ - заднеязычный смычный носовой звонкий согласный звук. Основание языка упирается в мягкое нёбо, закрывая выход воздуха через рот. Выдыхаемый воздух проходит через нос: аң - 'зверь', каң - 'сталь', соңга - 'окно'. При этом, мы обращали внимание на то, что звук [н] в тувинских словах встречается в середине и в конце.

Также, следует отмечать наличие групп 24 гласных звуков: 8 кратких $-a$,

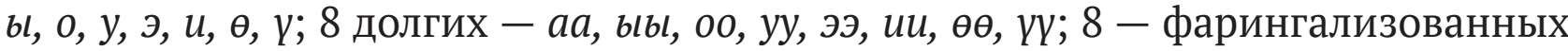
aъ, ыъ, оъ, уъ, эъ, иъ, өъ, үъ. Краткие гласные этимологически восходят к древнетюркским 8 гласным и не требуют особой характеристики, так как они в звуковом отношении соответствуют аналогичным гласным большинства тюркских языков.

Но одним из трудных вопросов при обучении тувинскому языку для русских учащихся является наличие долгих и фарингализованных гласных.

В письме долгие гласные обозначаются двумя буквами, например, оол 'мальчик', 'парень', чугаалаар - 'говорить', дээр - 'небо', мендилээр 'здороваться' и др. Неподготовленные слушатели произносят эти гласные как два отдельных звука. Наша задача состояла в пояснении как правильно их произносить одним звуком. Эта задача также подразумевала краткий экскурс в историю становления тувинского языка. Мы поясняли, что деление гласных на долгие и краткие в тувинском языке является исторически установившимся фактом, достаточно изученным тюркологами (Катанов, 1903; Исхаков, 1955; Пальмбах, 1955; Кунаа, 1957; Бичелдей, 1989; Дамбыра, 2005; Саая, 2006), использованным в качестве фонематического признака, который позволяет различать два разных слова: сын ('хребет') - сыыlн ('марал'), кир ('входить, заходить') - киир ('вносить, вводить').

После нескольких занятий затруднения при произношении долгих гласных устранены, т. к. произношение долгих гласных близки к ударным гласным русского языка.

Особое внимание при обучении тувинскому языку следует обратить на специфические звуки, при артикуляции которых активно участвует глотка. В тувинском языке эти звуки называются фарингализованными.

При этом, фарингализация гласных считается существенной особенностью вокализма тувинского языка, по сравнению с другими тюркскими языками 
(Куулар, 2012). Вопросу о происхождении фарингализации в тувинском языке посвящено немало работ ученых: А. А. Пальмбаха (Пальмбах, 1955), А. М.Щербак (Щербак, 1970), В. Г. Исхаков (Исхаков, 1955), В. М. Иллич-Свитыч (ИлличСвитыч, 1963), В. М. Наделяев (Наделяев, 1986), Б. И. Татаринцев (Татаринцев, 1974), Г. К. Вернер (Вернер, 1972), К. А. Бичелдей (Бичелдей, 2001) и др.

Фарингализованные гласные, подчиняясь внутренним фонетическим законам тувинского языка, употребляются в начале и середине многосложных слов, например, авттарывыс - 'наши лошади', чу(ъ)ртталга - 'жизнь', ки(ъ) жилер - 'люди', чи(ъ)гирзиг - 'сладкий' и др.

Фонетистами-тувиноведами было замечено, что в многосложных словах глоточный оттенок может сохраняться от начальных до последующих слогов. В связи с этим констатируется факт о том, что в тувинском языке возникает еще один тип гармонии гласных - гармония по фарингализации. По результатам экспериментальных работ К. А Бичелдей в своей монографии зафиксировал данное фонетическое явление и глубоко его исследовал (Бичелдей, 2001).

Фарингализация в тувинскомязыкетакжепринеопределенныхфонетических условиях распространяется в некоторых заимствованных из монгольского и русского языков словах: аъмдан - 'вкус', чеъчек - 'цветок', ыъшкола - 'школа', ыъстакан - 'стакан' и т. д.

Слушатели курсов долгое время не смогли воспринять и произнести слова с фарингализованными гласными, поскольку такие гласные наличествуют только в тувинском и тофаларском языках. Этот момент требует особых занятий, особого внимания.

Немалую трудность в обучении тувинском языку также составляет вопрос усвоения гармонии гласных.

Гласные в тувинском языке сочетаются в соответствии с законом сингармонизма. Гармония гласных проявляется по трем направлениям:

1) Нёбная (палатальная) - если в первом слоге слова находится гласных заднего ряда, то в последующих слогах корня и аффиксов также будут гласные того же ряда, если в первом слоге гласный переднего ряда, то дальше должны быть также гласные переднего ряда.

2) Губная (лабиальная) - если первым гласным корня слова является какойлибо из губных гласных $(o, y, \theta, \gamma)$, то во всех последующих словах корня и аффикса данного слова из узких гласных употребляются только губные (Куулар, 2012).

3) Гармония по фарингализованности - если гласный первого слога является фарингализованным, то в последующих слогах в пределах простого многосложного слога употребляются только фарингализованные оттенки соответствующих кратких и долгих гласных (Бичелдей, 2001). 
Гармония гласных является характерной особенностью тюркских, в том числе и тувинском, языках. Нашим слушателям было сложно понять эту особенность, они так и не смогли их освоить.

Согласные б- $n, \partial-m$ в начале слова. Согласные тувинского языка были объектом исследования А. Ч. Кунаа (Кунаа, 1957), С. В. Кечил-оол (Кечил-оол, 2006), С. Ф. Сегленмей (Сегленмей, 2010).

Существенной особенностью тувинского языка в области согласных считается наличие сильных придыхательных согласных [п’], [т'], [c'], [ш'], [х']. Слушателям было тяжело отличить звонковатый (Е. Б. Салзынмаа: ыыткырзымаар үн) согласный с придыхательным звуком [б] - [п'], [д] - [т'] в следующих парах: бар 'есть, имеется' - пар 'тигр', дал -'падать в обморок' - тал 'тальник' (Сат, Салзынмаа, 1980).

Трудность произношения этих согласных заключается в отсутствии аналогичных согласных в русском языке.

\section{Заключение}

Вопросы приобщения к языку региона, в котором проживают народы разных национальностей, в настоящее время стали актуальными. В Туве родной тувинский язык является связывающим звеном сохранения самобытности народа, его культуры, обычаев и традиций. Поэтому среди многонациональных жителей республики появилось немало желающих обучиться тувинскому языку и культуре. При этом в преподавании тувинского языка как неродного остро стоит проблема разработки ее методики.

Для решенияуказаннойвышепроблемынужныподготовленныеспециалисты. Первые опыты обучения тувинскому языку как неродному показывают, что преподавателям тувинского языка Тувинского государственного университета следует тщательно исследовать вопросы методики, а также пройти курсы повышения или переподготовки квалификации.

\section{СПИСОК ЛИТЕРАТУРЫ}

Баскаков, Н.А. (1952) К вопросу о классификации тюркских языков // Известия АН СССР. Отделение литературы и языка. Т. ХІ. Вып. 2. М. : Изд-во АН СССР. C. 121-134.

Бичелдей, К. А. (1989) Гласные тувинского языка в потоке речи : в 2 ч. Кызыл : ТнИИЯЛИ.

Бичелдей, К. А. (2001) Фарингализация в тувинском языке. М. : Издательство РУДН. 290 с. 
Вернер, Г. К. (1972) Происхождение фарингализации в тувинском и тофаларском языках // Советская тюркология. № 5. С. 17-24.

Вице-премьеры Александр Брокерт и Максим Тунев приняли участие в открытии курсов тувинского языка (2016) [Электронный ресурс] // Официальный портал Республики Тыва. 1 ноября. URL: http://gov.tuva.ru/ press_center/news/society/27985/ (дата обращения: 20.12.2017).

Дамбыра, И. Д. (2005) Вокализм каа-хемского говора в сопоставлении с другими говорами и диалектами тувинского языка. Новосибирск : Сибирский хронограф. 224 с.

Иллич-Свитыч, В. М. (1963) Алтайские дентальные t, d, D // Вопросы языкознания № 6. С. 37-56.

Иргит, Е. Л. (1996) Обучение орфографии тувинского языка в 5-6 классах в диалектных условиях : автореф. дис. ... канд. пед. н. М. 17 с.

Исхаков, Ф. Г. (1955) Долгие гласные в тюркских языках // Исследования по сравнительной грамматике тюркских языков : в 4 т. / под общ. ред. Н. К. Дмитриева. М. : АН СССР. Т. 1. Фонетика. 332 с. С. 160-174.

Исхаков, Ф. Г. (1955) Тувинский язык. Очерк по фонетике. М.-Л. : Изд-во АН СССР. 123 c.

Катанов, Н. Ф. (1903) Опыт исследования урянхайского языка с указанием главнейших родственных отношений его к другим языкам тюркского корня. Казань : Типо-лит. Имп. Казан. ун-та. 1600 с.

Кечил-оол, С. В. (2006) Типологическая специфика консонантизма сутхольского говора в системе говоров и диалектов тувинского языка : дисс. ... канд. филол. н. Новосибирск. 361 с.

Кунаа, А. Ч. (1957) Звуковая система современного тувинского языка. Кызыл : б. и. 57 с.

Куулар, Е. М. (2012) Юго-восточный диалект тувинского языка. Кызыл : Тув. госуниверситет. 213 с.

Март-оол, К. Б. (1969) Методика преподавания местоимения родного языка в 5 классе тувинских школ : автореф. дис. ... канд. пед. н. Л. 23 с.

Март-оол, К. Б. (2002) 5-9 класстарга тыва дылды башкылаарының методиказы [Методическое пособие для учителей тувинского языка для 5-9 классов]. Кызыл : Тываның ном үндүрер чери. 272 с. (На тув. яз.).

Наделяев, В. М. (1986) У истоков тувинского языка // Исследования по тувинской филологии / отв. ред. Д. А. Монгуш. Кызыл : ТНИИЯЛИ. 156 с. С. 53-63.

Оргу, К. Х. (1967) Тыва дылды ортумак школага башкылаарының методиказы [Методическое пособие для учителей для преподавания тувинского языка в средней школе]. Кызыл : Тываның ном үңдүрер чери. 445 с. (На тув. яз.). 
Пальмбах, А. А. (1955) Долгие и полудолгие гласные тувинского языка // Исследования по сравнительной грамматике тюркских языков : в 4 т. / под общ. ред. Н. К. Дмитриева. М. : АН СССР. Т. 1. Фонетика. 332 с. С. 171-181.

Саая, О. М. (2005) Долгие гласные тувинского языка (в сравнении с тюркскими языками Южной Сибири и монгольскими) : автореф. дисс. ... канд. филол. н. Новосибирск. 21 с.

Сат, Ш. Ч., Салзынмаa, Е. Б. (1980) Амгы тыва литературлуг дыл [Тувинский литературный язык]. Кызыл. 257 с. (На тув. яз.).

Сегленмей, С. Ф. (2010) Консонантизм тувинского языка. Экспериментальнофонетическое исследование. Кызыл : РИО ТывГУ. 142 с.

Татаринцев, Б. И. (1974) Характер изменений звукового комплекса с интервокальным k в тувинском языке // Советская тюркология. № 6. С. 18-27.

Теоретические основы методики обучения иностранным языкам (2017) [Электронный ресурс]: Учебно-методическое пособие / Дальневосточный федеральный университет, Школа педагогики; [авт.-сост. Т. И. Скрипникова]. Владивосток: Дальневосточный Федеральный университет. URL: https://www. dvfu.ru/schools/school_of_education/e-ublications/2017/skripnikova-ti_metodika_ obucheniya-inostr_yazykam_lektsii_2017.pdf (дата обращения: 01.12.2017).

Щербак, А. М. (1970) Сравнительная фонетика тюркских языков. Л. : Наука, Ленинградское отделение.

Дата поступления: 12.01.2018 2.

\section{REFERENCES}

Baskakov, N. A. (1952) K voprosu o klassifikatsii tiurkskikh iazykov [On the classification of Turkic languages]. In: Izvestiia AN SSSR. Otdelenie literatury i iazyka. Vol. XI, issue 2. Moscow, AN SSSR Publ. Pp. 121-134. (In Russ.).

Bicheldei, K. A. (1989) Glasnye tuvinskogo iazyka v potoke rechi [Vowels of Tuvan language in the flow of speech]: in 2 vol. Kyzyl. (In Russ.).

Bicheldei, K. A. (2001) Faringalizatsiia $v$ tuvinskom iazyke [Pharingealization in the Tuvan language]. Moscow, RUDN Publ. 290 p. (In Russ.).

Verner, G. K. (1972) Proiskhozhdenie faringalizatsii v tuvinskom i tofalarskom iazykakh [Origin of pharingealization in Tuvan and Tofalar language]. Sovetskaia tiurkologiia, no. 5, pp. 17-24. (In Russ.).

Vitse-prem'ery Aleksandr Brokert i Maksim Tunev priniali uchastie v otkrytii kursov tuvinskogo iazyka [Vice-premieres Aleksandr Brockert and Maxim Tunev took part in the opening of Tuvan language courses] (2016). Ofitsial'nyi portal Respubliki Tuva, 1 November [online] Available at: http://gov.tuva.ru/press_center/news/society/27985/ (access date: 20.12.2017). (In Russ.). 
Dambyra, I. D. (2005) Vokalizm kaa-khemskogo govora $v$ sopostavlenii s drugimi govorami i dialektami tuvinskogo iazyka [Vocalism of the Kaa-Khem dialect in comparison with other patois and dialects of Tuvan language]. Novosibirsk, Sibirskii khronograf. 224 p. (In Russ.).

Illich-Svitych, V. M. (1963) Altaiskie dental'nye t, d, D [The Altai dental t, d, D]. Voprosy iazykoznaniia, no. 6, pp. 37-56. (In Russ.).

Irgit, E. L. (1996) Obuchenie orfografii tuvinskogo iazyka v 5-6 klassakh $v$ dialektnykh usloviiakh [Teaching of spelling of Tuvan language in 5-6 grades in dialect conditions]: Thesis of Diss.... Candidate of Pedagogy. Moscow. 17 p. (In Russ.).

Iskhakov, F. G. (1955) Dolgie glasnye v tiurkskikh iazykakh [Long vowels in Turkic Languages]. In: Issledovaniia po sravnitel'noi grammatike tiurkskikh iazykov [Studies on Comparative Grammar of Turkic Languages]: in 4 vol. / ed. by N. K. Dmitriev. Moscow, AN SSSR. Vol. 1. Fonetika [Phonetics]. 332 p. Pp. 160-174. (In Russ.).

Iskhakov, F. G. (1955) Tuvinskii iazyk. Ocherk po fonetike [Tuvan language. An essay on phonetics]. Moscow, Leningrad, AN SSSR Publ. 123 p. (In Russ.).

Katanov, N. F. (1903) Opyt issledovaniia uriankhaiskogo iazyka s ukazaniem glavneishikh rodstvennykh otnoshenii ego $k$ drugim iazykam tiurkskogo kornia [An attempt of studying Uriankh language with indication of its major links to other languages of Turkic origin]. Kazan', Tipo-lit. Imp. Kazan. un-ta. 1600 p. (In Russ.).

Kechil-ool, S. V. (2006) Tipologicheskaia spetsifika konsonantizma sut-khol'skogo govora $v$ sisteme govorov $i$ dialektov tuvinskogo iazyka [Typological specificity of the consonantism of the Sut-Khol dialect in the system of patois and dialects of Tuvan language]: Diss.... Candidate of Philology. Novosibirsk. 361 p. (In Russ.).

Kunaa, A. Ch. (1957) Zvukovaia sistema sovremennogo tuvinskogo iazyka [Sound system of modern Tuvan language]. Kyzyl, no publisher. 57 p. (In Russ.).

Kuular, E. M. (2012) Iugo-vostochnyi dialekt tuvinskogo iazyka [Southeast dialect of Tuvan language]. Kyzyl, Tuv. gosuniversitet. 213 p. (In Russ.).

Mart-ool, K. B. (1969) Metodika prepodavaniia mestoimeniia rodnogo iazyka $v$ 5 klasse tuvinskikh shkol [The technique of teaching the pronoun of the native language in the 5th grade of Tuvan schools]: Thesis of Diss.... Candidate of Pedagigy. Leningrad. 23 p. (In Russ.).

Mart-ool, K. B. (2002) 5-9 klasstarga tyva dyldy bashkylaarynyň metodikazy [Methodological guide for teachers of Tuvan language for 5-9 grades]. Kyzyl, Tyvanyň nom ündürer cheri. 272 p. (In Tuv.).

Nadeliaev, V. M. (1986) U istokov tuvinskogo iazyka [At the origins of Tuvan language]. In: Issledovaniia po tuvinskoi filologii [Studies of the Tuvan Philology] / ed. by D. A. Mongush. Kyzyl, TNIIIaLI. 156 p. Pp. 53-63. (In Russ.). 
Orgu, K. Kh. (1967) Tyva dyldy ortumak shkolaga bashkylaarynyň metodikazy [Methodological guide for teachers to teach the Tuvan language in secondary school]. Kyzyl, Tyvanyň nom ündürer cheri. 445 p. (In Tuv.).

Pal'mbakh, A. A. (1955) Dolgie i poludolgie glasnye tuvinskogo iazyka [Long and semi-long vowels of Tuvan language]. In: Issledovaniia po sravnitel'noi grammatike tiurkskikh iazykov [Studies on Comparative Grammar of Turkic Languages]: in 4 vol. / ed. by N. K. Dmitriev. Moscow, AN SSSR. Vol. 1. Fonetika [Phonetics]. 332 p. Pp. 171-181. (In Russ.).

Saaia, O. M. (2005) Dolgie glasnye tuvinskogo iazyka (v sravnenii s tiurkskimi iazykami Iuzhnoi Sibiri i mongol'skimi) [Long vowels of Tuvan language (in comparison with the Turkic languages of South Siberia and Mongolian)]: Thesis of Diss.... Candidate of Philology. Novosibirsk. 21 p. (In Russ.).

Sat, Sh. Ch. and Salzynmaa, E. B. (1980) Amgy tyva literaturlug dyl [Tuvan literary language]. Kyzyl. 257 p. (In Tuv.).

Seglenmei, S. F. (2010) Konsonantizm tuvinskogo iazyka. Eksperimental'no-foneticheskoe issledovanie [Consonantism of the Tuvan language. Experimental phonetic study]. Kyzyl, RIO TyvGU. 142 p. (In Russ.).

Tatarintsev,B.I.(1974) Kharakter izmenenii zvukovogo kompleksa s intervokal'nym $\mathrm{k} v$ tuvinskom iazyke [The nature of changes in the sound complex with intervocal $\mathrm{k}$ in the Tuvan language]. Sovetskaia tiurkologiia, no. 6, pp. 18-27. (In Russ.).

Teoreticheskie osnovy metodiki obucheniia inostrannym iazykam [Theoretical basis of foreign language teaching methodology] (2017) : Uchebno-metodicheskoe posobie / T. I. Skripnikova. Vladivostok, Dal'nevostochnyi Federal'nyi universitet [online] Available at https://www.dvfu.ru/schools/school_of education/e-ublications/2017/ skripnikova-ti_metodika_obucheniya-inostr_yazykam_lektsii_2017.pdf (access date: 01.12.2017). (In Russ.).

Shcherbak, A. M. (1970) Sravnitel'naia fonetika tiurkskikh iazykov [Comparative phonetics of Turkic languages]. Leningrad, Nauka, Leningradskoe otdelenie. (In Russ.).

Submission date: 12.01.2018.

\section{Для цитирования:}

Сувандии Н. Д., Куулар Е. М. Некоторые сложные вопросы методики обучения тувинскому языку как неродному [Электронный ресурс] // Новые исследования Тувы. 2018, № 1. URL: https:/nit.tuva.asia/nit/article/view/753 (дата обращения: дд.мм.гг.). DOI: $10.25178 /$ nit.2018.1.2

\section{For citation:}

Suvandii N. D. and Kuular E. M. Some complications in the methodology of teaching Tuvan to non-native speakers. The New Research of Tuva, 2018, no. 1 [on-line] Available at: https://nit.tuva.asia/nit/article/view/753 (accessed: ...). DOI: 10.25178/nit.2018.1.2 